Article

\title{
Improved Brønsted to Lewis (B/L) Ratio of Co- and Mo-Impregnated ZSM-5 Catalysts for Palm Oil Conversion to Hydrocarbon-Rich Biofuels
}

\author{
Teguh Riyanto ${ }^{1,2} \mathbb{D}$, Istadi Istadi ${ }^{1,2, *} \mathbb{C}$, Bunjerd Jongsomjit ${ }^{3}$, Didi D. Anggoro ${ }^{1}$, Aryadita Ayu Pratama ${ }^{1}$ \\ and Muhammad Aviv Al Faris ${ }^{1}$ \\ 1 Department of Chemical Engineering, Faculty of Engineering, Universitas Diponegoro, Semarang 50275, \\ Indonesia; teguh_ryt@student.undip.ac.id (T.R.); anggorophd@gmail.com (D.D.A.); \\ aryadita23@gmail.com (A.A.P.); farisaviv7@gmail.com (M.A.A.F.) \\ 2 Laboratory of Plasma-Catalysis (R3.5), Center of Research and Services-Diponegoro \\ University (CORES-DU), Universitas Diponegoro, Semarang 50275, Indonesia \\ 3 Department of Chemical Engineering, Faculty of Engineering, Chulalongkorn University, Bangkok 10330, \\ Thailand; bunjerd.j@chula.ac.th \\ * Correspondence: istadi@che.undip.ac.id
}

check for updates

Citation: Riyanto, T.; Istadi, I.; Jongsomjit, B.; Anggoro, D.D.; Pratama, A.A.; Faris, M.A.A. Improved Brønsted to Lewis (B/L) Ratio of Co- and Mo-Impregnated ZSM-5 Catalysts for Palm Oil Conversion to Hydrocarbon-Rich Biofuels. Catalysts 2021, 11, 1286. https://doi.org/10.3390/catal11111286

Academic Editor: Sagadevan Suresh

Received: 8 September 2021

Accepted: 23 October 2021

Published: 26 October 2021

Publisher's Note: MDPI stays neutral with regard to jurisdictional claims in published maps and institutional affiliations.

Copyright: (c) 2021 by the authors. Licensee MDPI, Basel, Switzerland. This article is an open access article distributed under the terms and conditions of the Creative Commons Attribution (CC BY) license (https:/ / creativecommons.org/licenses/by/ $4.0 /)$.
Abstract: The purposes of this study are to investigate the effect of metal (Co and Mo) impregnation to ZSM-5 catalysts on the Brønsted to Lewis (B/L) ratio as the active sites of cracking reaction, and the catalysts' performance testing for palm oil cracking to produce hydrocarbon-rich biofuels. Both metals were impregnated on the ZSM- 5 catalyst using a wet-impregnation method. The catalysts were characterized using X-ray diffraction (XRD), X-ray Fluorescence (XRF), Scanning Electron Microscopy (SEM), Brunauer-Emmett-Teller (BET), and Pyridine-probed Fourier-Transform Infrared (Py-FTIR) spectroscopy methods. The catalysts were tested on the cracking process of palm oil to biofuels in a continuous fixed-bed catalytic reactor. In order to determine the composition of the organic liquid product (OLP, biofuels), the product was analyzed using a gas chromatography-mass spectrometry (GC-MS) method. The results showed that the co-impregnation of Co and Mo to ZSM-5 highly increased the Brønsted to Lewis acid site (B/L) ratio, although the total number of acid sites decreased. However, the impregnation of Co and Mo on the ZSM-5 decreased the surface area of catalysts due to pore blocking by metals, while the $\mathrm{B} / \mathrm{L}$ ratio of the catalysts increased. It was obtained that by utilizing Co- and Mo-impregnated ZSM- 5 catalysts, the hydrocarbons product selectivity increased from $84.32 \%$ to $95.26 \%$; however, the yield of biofuels decreased from $67.57 \%$ to $41.35 \%$. The increase in hydrocarbons product selectivity was caused by the improvement of the Brønsted to Lewis (B/L) acid sites ratio.

Keywords: palm oil; catalytic cracking; biofuels; hydrocarbon; Co-Mo/ZSM-5; Brønsted-Lewis acid sites

\section{Introduction}

We are facing the fact that the energy demand is increasing. Nowadays, fossil-based fuels are still the primary energy that supplies the daily energy demand. However, fossil fuel resources will decline, and they can be exhausted due to their non-renewable nature. Moreover, it is not environmentally friendly due to the high contaminant compounds that can harm the environment. Therefore, it is important to develop a renewable, sustainable, environmentally friendly energy resource to supply the energy demand. Biofuel appears to be a promising energy resource to substitute, or at least to support, the fossil fuels energy resource. It is renewable and sustainable since it is produced through biomass conversion, such as vegetable oil. One of the most developed vegetable oil-based biofuels is produced via the catalytic cracking process of palm oil [1,2]. Moreover, biofuels are environmentally friendly because biofuels that are produced through catalytic cracking of vegetable oil 
have no pollutants, such as sulfur, nitrogen, and heavy metals [3]. Since biofuels have no sulfur and nitrogen-containing compounds that can be released to the environment as SOx and NOx [3], the combustion process of these biofuels produces better emissions than fossil fuels.

The most developed biofuels are palm oil-based biofuels that contain triglyceride components. The cracking process, which can be conducted through pyrolysis (thermal cracking), catalytic cracking, and plasma-assisted catalytic cracking, was reported as a promising process in producing biofuels from palm oil [4]. It was confirmed that catalysts were the most important substance in catalytic cracking. Catalysts are responsible for specifying the components in the biofuels. The main compounds in the biofuels are hydrocarbons and oxygenated compounds. However, oxygenated compounds are avoided because they can reduce the heat capacity, as well as the heating value of biofuels $[5,6]$. Since the catalysts are responsible for this circumstance, developing a catalyst that can support both cracking and deoxygenation reactions is reasonable.

Zeolite catalysts are the most developed catalysts due to the high surface area, which has an important role in the mass transfer process in the catalytic cracking process [7]. Some zeolites are utilized for biomass catalytic cracking, including HY, ZSM-5, and H-Beta [6,8]. Gurdeep Singh et al. [6] used ZSM-5-based catalysts to produce biogasoline from linoleic acid. They reported that ZSM-5-based catalysts effectively produce hydrocarbon-rich biofuels, especially the short-chain hydrocarbons in the range of biogasoline. Therefore, it is necessary to develop a ZSM-5-based catalyst to produce hydrocarbon-rich biofuels from palm oil. However, using ZSM-5-based catalysts produces aromatic compounds because the ZSM- 5 catalyst has a unique pore structure and pore size similar to aromatic compounds, such as toluene, xylene, and benzene $[6,9]$. Even though the octane number of biofuels can be increased by the presence of aromatic compounds, they may be released as benzene, which is a toxic substance, to the environment [6]. Therefore, the number of aromatic compounds should be controlled in biofuels. Some modifications should be made to improve the ZSM- 5 catalyst for biofuels production so that the hydrocarbon products can be increased while the aromatic compounds can be decreased.

The modification using transition metals on the zeolite catalysts can improve the performance of catalysts to produce biofuels. Istadi et al. [2] utilized nickel (Ni) and cobalt (Co) to modify the HY catalyst for palm oil cracking. The impregnation of $\mathrm{Ni}$ and $\mathrm{Co}$ on the HY catalyst did not significantly change the yield of liquid fuels; however, the hydrocarbons were massively increased. Nevertheless, the impregnation of $\mathrm{Ni}$ on $\mathrm{HY}$ led to increasing coke formation. Some studies also reported that $\mathrm{Ni}$ has a high affinity leading to coke formation [2,6,10]. Haji Morni et al. [11] modified the ZSM-5 using nickel (Ni) and molybdenum (Mo) for the co-pyrolysis of sewage sludge-sawdust. It was reported that $\mathrm{MoO}_{3}$ could reduce the aromatic compounds. However, incorporating $\mathrm{NiO}$ with $\mathrm{MoO}_{3}$ could massively increase the aromatic compounds, as well as the oxygenated compounds [11]. Botas et al. [10] reported that the Mo-modified nanocrystalline ZSM-5 zeolite could increase the aromatic compounds on the catalytic conversion of rapeseed oil. However, the studies concerning the modification of Co and Mo metals on the ZSM-5 dedicated for cracking palm oil to biofuels are still limited. Therefore, the aims of this study are to investigate the effect of metal's (Co and Mo) modification to the ZSM-5 catalysts focusing on the Brønsted to Lewis (B/L) ratio and the catalysts' performance for palm oil cracking to produce hydrocarbon-rich biofuels. The modification of the ZSM-5 catalyst using Co and Mo is expected to increase the hydrocarbon products so that this study investigates the relation of catalyst properties with the catalyst activity to produce hydrocarbon-rich biofuels. Moreover, the hydrocarbons distributions are investigated to understand the effect of Co and Mo impregnation of the ZSM- 5 catalyst on the formation of aromatic compounds. 


\section{Results and Discussion}

\subsection{Catalysts Characterizations}

The XRD analysis was conducted to analyze the crystal structure of the catalysts. Figure 1 presents the XRD patterns of all catalysts. Based on Figure 1, the catalysts exhibit characteristic diffraction peaks of the MFI structure (ZSM-5). The characteristic quintet peaks of the ZSM- 5 catalyst are found at $2 \theta=23-25^{\circ}$ [12]. In this study, the peaks correspond to the characteristic quintet of ZSM-5 appear at $2 \theta=23.2,23.4,23.8,24.1$, and $24.5^{\circ}$ (Figure 1). Generally, these peaks are used to determine the relative crystallinity of ZSM-5-based catalysts. During the calculation, the ZSM-5 sample is used as the reference. The relative crystallinity of catalysts is $100 \%, 98.3 \%, 89.0 \%$, and $94.6 \%$ for ZSM- 5 , Co/ZSM-5, Mo/ZSM-5, and Co-Mo/ZSM-5, respectively. It can be concluded that the relative crystallinity of catalysts decreases after metals impregnation. Moreover, there is no significant difference in XRD patterns among all catalysts. This fact confirms that the crystal structure of the catalyst is not significantly changed after the metal impregnation [2]. Based on these facts, it can be suggested that the decrease in relative crystallinity is attributed to the coverage of metal species on the catalyst's surface instead of the framework destruction. This fact is in line with Huang et al. [13], who reported that the X-ray absorption by the metals might cause a decrease in relative crystallinity of cerium-modified HY catalysts.
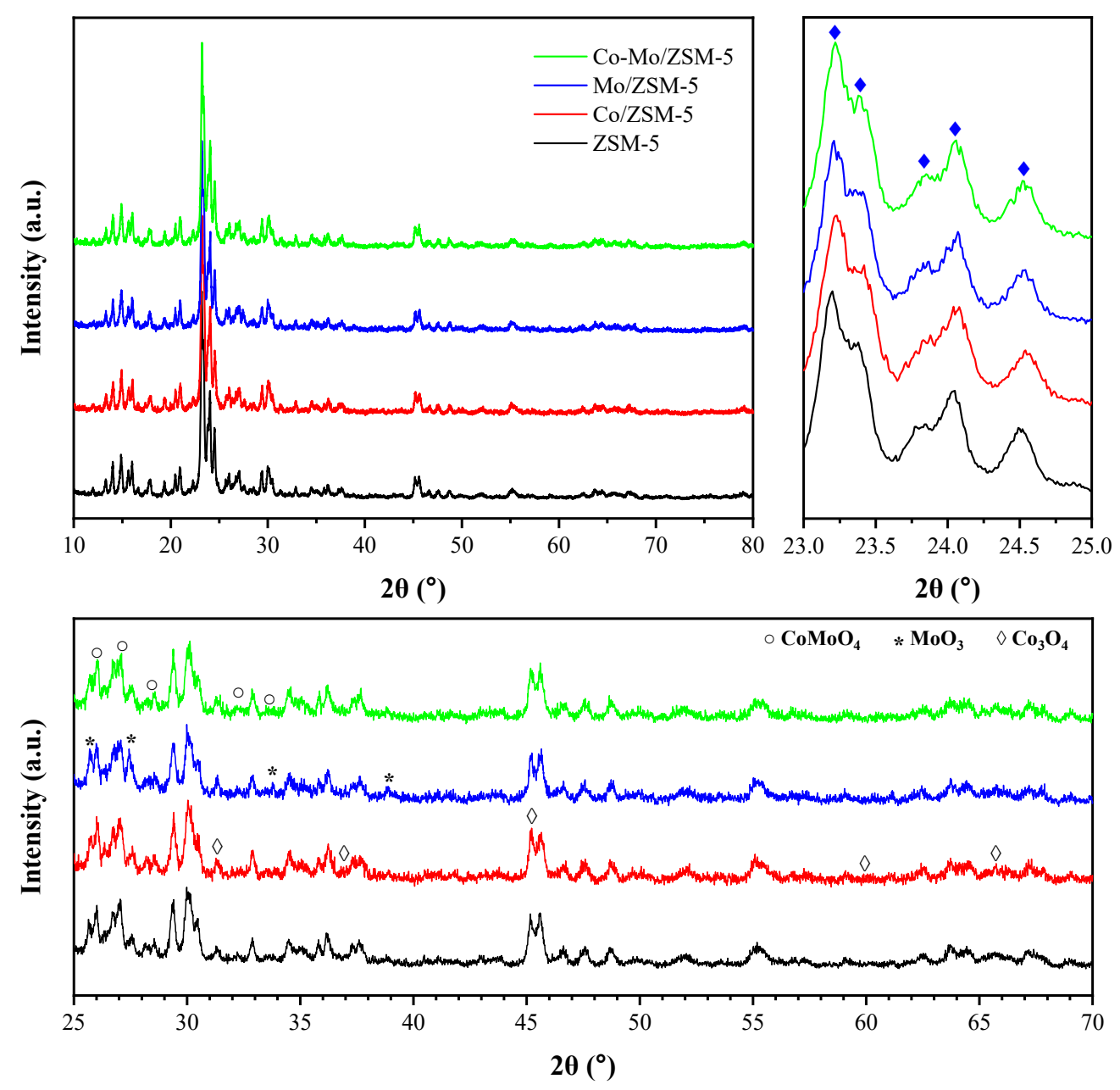

Figure 1. XRD patterns of the catalysts.

Concerning the impregnated metals on the ZSM- 5 catalyst, more intense investigation on the corresponding characteristic peaks has been conducted. As shown in Figure 1, new peaks appear in the Co/ZSM-5 catalyst at $2 \theta=31.3,36.8,45,59.4$, and $65.3^{\circ}$, corresponding to the $\mathrm{Co}_{3} \mathrm{O}_{4}$ (JCPDS-42-1467) [14-16]. It can be observed that the characteristic peaks of 
$\mathrm{Co}_{3} \mathrm{O}_{4}$ at $2 \theta=31.3$ and $45^{\circ}$, overlap with the characteristic peaks of ZSM-5. However, these peaks have a higher intensity than those that appear in ZSM- 5 catalysts, indicating the peaks of $\mathrm{Co}_{3} \mathrm{O}_{4}$ appear and overlap with the corresponding peaks of ZSM-5 at the same Bragg angle. Concerning the Mo/ZSM-5 catalyst, new peaks appear at $2 \theta=25.7,27.4,33.7$, and $38.8^{\circ}$, corresponding to $\alpha-\mathrm{MoO}_{3}$ (orthorhombic $\mathrm{MoO}_{3}$ ) (JCPDS-05-0508) [17-19]. It can be seen that the peak at $2 \theta=25.7^{\circ}$ in the Mo/ZSM- 5 catalyst overlaps with the peak in ZSM-5, in which the peak in Mo/ZSM-5 is higher than in the ZSM-5 catalyst. On the other hand, the peak at $2 \theta=27.6^{\circ}$ in ZSM- 5 is sharpened /heightened and shifted to $27.4^{\circ}$ due to the presence of the highest corresponding peak of $\alpha-\mathrm{MoO}_{3}$. Wang et al. [17] reported that the highest diffraction peak of $\alpha-\mathrm{MoO}_{3}$ appears at $2 \theta=27.36^{\circ}$; meanwhile, Sen et al. [18] reported that it appears at $2 \theta=27.32^{\circ}$. Moreover, new peaks appear at $2 \theta=26.5,27.3$, $28.2,32.2$, and $33.8^{\circ}$ in the Co-Mo/ZSM- 5 catalyst, corresponding to $\beta-\mathrm{CoMoO}_{4}$ (JCPDS21-0868) [20-23]. Based on this analysis, it can be deduced that the metals have been impregnated with the ZSM- 5 catalyst due to the appearance of the peaks corresponding to the impregnated metals. It is also proven by XRF analysis, as reported in Table 1.

As can be observed in Figure 1, the peaks correspond to the impregnated metals $\left(\mathrm{Co}_{3} \mathrm{O}_{4}, \mathrm{MoO}_{3}\right.$, and $\left.\mathrm{CoMoO}_{4}\right)$ have low intensity, suggesting that the metals are dispersed on the catalysts $[2,13]$. In addition, the diffraction peaks are relatively broad, indicating that the metal clusters obtained are small in size. As shown in the SEM image (Figure 2), there is no difference in the surface appearance of ZSM- 5 and Co-Mo/ZSM-5 catalysts. This confirms that there are no significant new bulk phases generated after the metal impregnation process. Moreover, the metal clusters are not detected in the SEM image because the metal clusters are small, as suggested through XRD analysis. In addition, it also confirms that new inhomogeneities are not observed after impregnation. Since the metal clusters are small, it is reasonable to conclude that the metals are dispersed on catalysts. Therefore, based on the XRD analysis and confirmed by the SEM image, it is suggested that the metal clusters are small and dispersed on the catalysts.
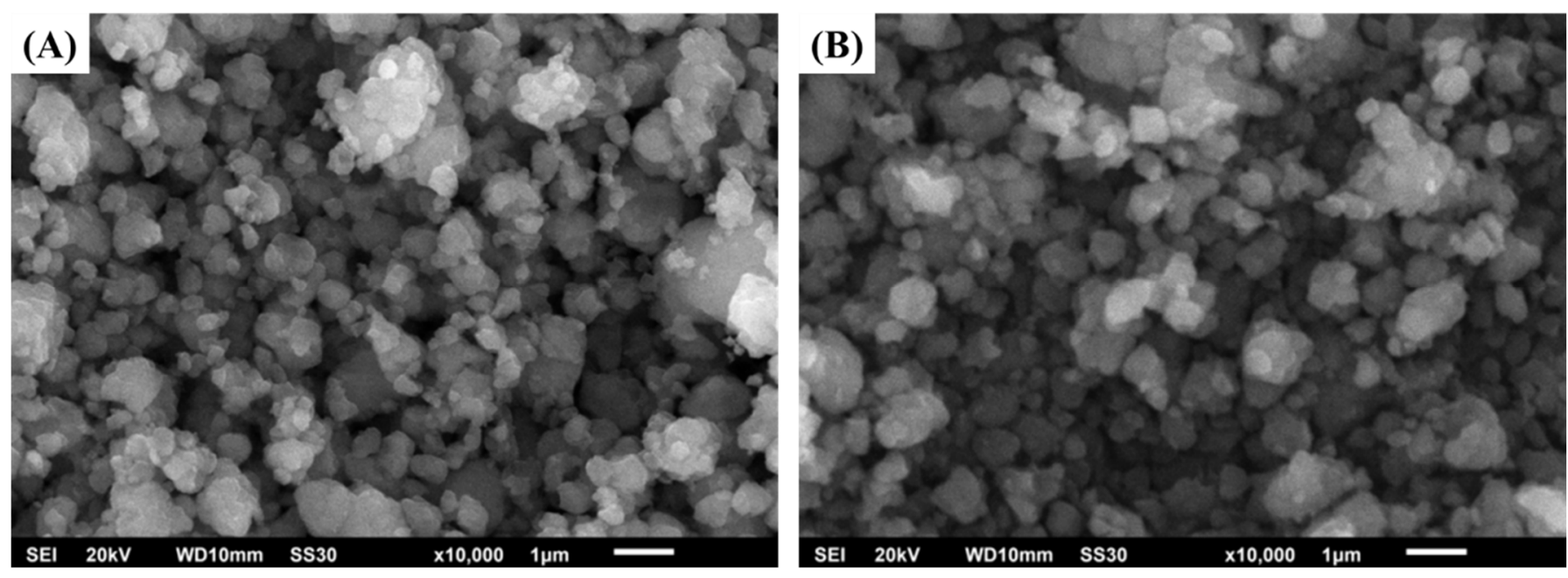

Figure 2. SEM images of (A) ZSM-5 and (B) Co-Mo/ZSM-5.

In addition, the catalyst's surface area is one of the important catalyst characteristics affecting the cracking process [24]. In order to determine the catalyst's surface area after metal impregnation, $\mathbf{N}_{2}$-physisorption data at a relative pressure $\left(p / p^{\circ}\right)$ of $0.05-0.35$ are used for calculation using the BET method [25]. As shown in Table 1, the ZSM-5 catalyst shows the highest surface area, while the Co-Mo/ZSM- 5 catalyst shows the lowest surface area. Moreover, the catalyst's surface area tends to decrease from 396.50 to $315.50 \mathrm{~m}^{2} / \mathrm{g}$ after metal impregnation. This decreasing surface area trend demonstrates that small metals clusters are generated on the pore mouths and/or inside the pores. As a result, the pores are partially blocked, resulting in a decrease in surface area. Following some 
previously reported studies, this finding has been obtained that the addition of metallic elements might cause a partial blockage effect towards the zeolite channel $[1,13]$. Therefore, it is deduced that the impregnation of some metals, such as Co and Mo, in ZSM- 5 catalysts can partially block the pores, reducing the catalyst's surface area.

Table 1. Physicochemical properties of the catalysts.

\begin{tabular}{|c|c|c|c|c|c|c|c|}
\hline \multirow{2}{*}{ Catalysts } & \multicolumn{2}{|c|}{ Metal Content (\%wt) } & \multirow{2}{*}{ Surface Area $\left(\mathrm{m}^{2} / \mathrm{g}\right)$} & \multicolumn{3}{|c|}{ Acid Sites $(\mu \mathrm{mol} / \mathrm{g})$} & \multirow{2}{*}{ B/L Ratio $\ddagger$} \\
\hline & Co & Mo & & Lewis & Brønsted & Total & \\
\hline ZSM-5 & - & - & 396.50 & 21.21 & 1.71 & 22.92 & 0.081 \\
\hline Co/ZSM-5 & 4.85 & - & 360.46 & 41.93 & 1.46 & 43.39 & 0.035 \\
\hline Mo/ZSM-5 & - & 4.98 & 331.07 & 22.68 & 1.81 & 24.49 & 0.080 \\
\hline Co-Mo/ZSM-5 & 2.62 & 3.39 & 315.50 & 9.45 & 1.09 & 10.54 & 0.116 \\
\hline
\end{tabular}

$\ddagger$ Ratio of Brønsted and Lewis acid sites.

The total catalyst acidity and the identification of Brønsted and Lewis acid sites are determined using a pyridine-probed FT-IR analysis. Prior to FT-IR analysis, pyridine was adsorbed on the catalysts. Both physisorbed and chemical bonded pyridine molecules after adsorption are found in the absorbance band, giving an estimation of total acidity [13]. Since the adsorbed pyridine is evacuated at $150{ }^{\circ} \mathrm{C}$, it is assumed that the physisorbed pyridine is removed, while the band recorded represents the chemisorbed pyridine, and the acidity measured is considered as strong acidity $[13,26]$. The absorbance bands around 1545 and $1455 \mathrm{~cm}^{-1}$ are used to determine the intensity of Brønsted and Lewis acid sites, respectively $[27,28]$. The Lewis acid site represents the electron acceptor active site. On the other hand, the Brønsted acid site represents a proton donor active site from the $\mathrm{Si}(\mathrm{OH})-\mathrm{Al}$ bridge in a zeolitic catalyst [29].

Figure 3 depicts the IR spectra of catalysts after pyridine adsorption. As depicted in Figure 3, all catalysts have absorbance bands around 1545 and $1455 \mathrm{~cm}^{-1}$. It means that all catalysts have both Brønsted and Lewis acid sites, in which the intensity of Brønsted and Lewis acid sites and their ratios are presented in Table 1. As can be observed, the metal impregnation affects the acidity of the catalysts. The single metal impregnation, Co/ZSM-5 and Mo/ZSM-5 increases the total acidity, in which the Co/ZSM-5 shows the highest total acidity. As shown in Table 1, the Brønsted acid sites remain constant after metal impregnation. It is true since the presence of the Brønsted acid site is a function of zeolite content, and its density is determined by the ratio of the silicon/alumina content [30]. As there is no treatment of ZSM-5 prior to the metal impregnation, it is suggested that the silicon to alumina ratio in the ZSM-5 framework remains unchanged. It is confirmed with the $\mathrm{XRD}$ analysis result, indicating no crystal structure changing, suggesting no change in silicon to alumina ratio in the ZSM-5 framework.

As can be observed, the metal (Co or Mo) impregnation highly enhances the Lewis acid site rather than the Brønsted acid site. As expected, the addition of Co or Mo can increase the Lewis acid site and decrease the $\mathrm{B} / \mathrm{L}$ ratio. The Lewis acid site reaches the highest amount in Co/ZSM-5 and the lowest in Co-Mo/ZSM-5. Anggoro et al. [31] reported that the higher Lewis acid sites after metal impregnation are attributed to the presence of unoccupied orbitals of transition metals that can accept electrons. However, the co-impregnation of both Co and Mo tends to decrease in both Brønsted and Lewis acid sites, as well as the total acidity. This decrease is attributed to the pore blockage by the metals cluster. As reported above, the metals cluster partially blocks the pores so that the surface area decreases. As a consequence, the acid sites are also blocked, resulting in a decrease in the accessible Lewis acid site and leading to an increase in the $\mathrm{B} / \mathrm{L}$ ratio. The decrease in Lewis acid site due to the loading of both Co and Mo was also reported by Sadiq et al. [32]. They suggested that the loading of both Co and Mo could decrease the Lewis acid site due to the formation of a $\mathrm{CoMoO}_{4}$ metal cluster [32] and/or the formation of inactive $\mathrm{Al}_{2}\left(\mathrm{MoO}_{4}\right)_{3}$ [33]. 


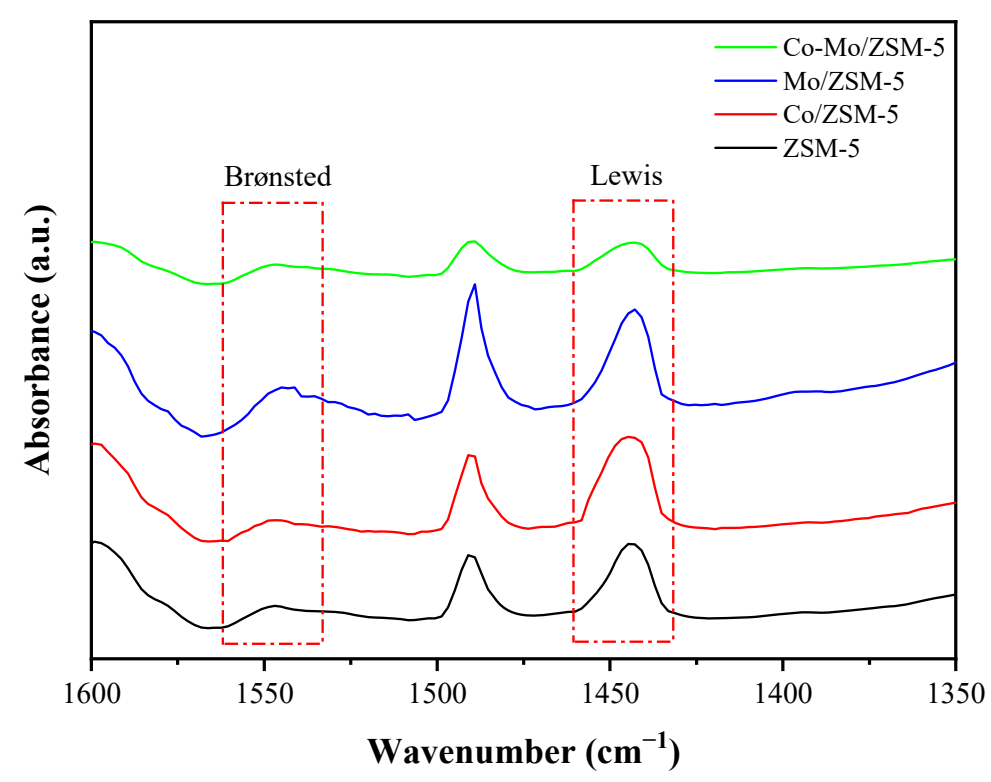

Figure 3. IR spectra of catalysts after pyridine adsorption.

\subsection{Catalytic Reaction Process Performance Test}

The catalytic performances of the Co and Mo-modified ZSM-5 catalysts were evaluated through palm oil cracking to biofuels in a continuous fixed-bed catalytic reactor. The catalytic performances of Co and Mo-modified ZSM- 5 catalysts are presented in Figure 4. The ZSM-5 catalyst obtains the highest yield of OLP (67.57\%), while the Co-Mo/ZSM5 obtains the lowest yield of OLP (41.35\%). Reversely, the ZSM-5 catalyst obtains the lowest yield of gas (31.35\%), and the Co-Mo/ZSM-5 obtains the highest (57.05\%). It can be observed that the ZSM-5 has a low $\mathrm{B} / \mathrm{L}$ ratio and Co-Mo/ZSM-5 has a high $\mathrm{B} / \mathrm{L}$ ratio. It is shown that a high $\mathrm{B} / \mathrm{L}$ ratio leads to the production of the gas fraction. Moreover, it confirms that the Brønsted acid site leads to more cracking activity. It is true since the Brønsted acid site is responsible for the cracking reaction $[34,35]$. It is widely known that the Brønsted acid site forms carbonium or carbenium ions, which can initiate the cracking process [35]. However, this trend is violated by Co/ZSM-5, which contains the lowest B/L ratio. As the $\mathrm{B} / \mathrm{L}$ ratio is the lowest, it is supposed that it would produce the highest yield of OLP; however, the highest yield of OLP is obtained by the ZSM- 5 catalyst. It confirms that the yield of products is not only affected by the $\mathrm{B} / \mathrm{L}$ ratio but also affected by the total acid site. A high acid site amount increases the cracking reaction so that the yield of OLP decreases and the yield of gas increases [2].

Concerning the coke formation, the Co/ZSM-5 gives the highest coke yield, and the Co-Mo/ZSM-5 obtains the lowest yield of coke. It is clearly found that the coke formation depends on the acid site distribution. The catalyst with a high Lewis acid site produces high coke, while the catalyst with a low Lewis acid site produces low coke. It shows that the Lewis acid site is highly active in coke formation. This finding is in accordance with some previous reports $[2,34,35]$. Based on these findings, it is reasonable to conclude that the Lewis acid site is the active site for the coke formation and the Brønsted acid site is the active site for the cracking reaction. In addition, coke formation is highly dependent on the total acid site amount of the catalysts. Catalysts with high acidity lead to high coke formation [36]. 


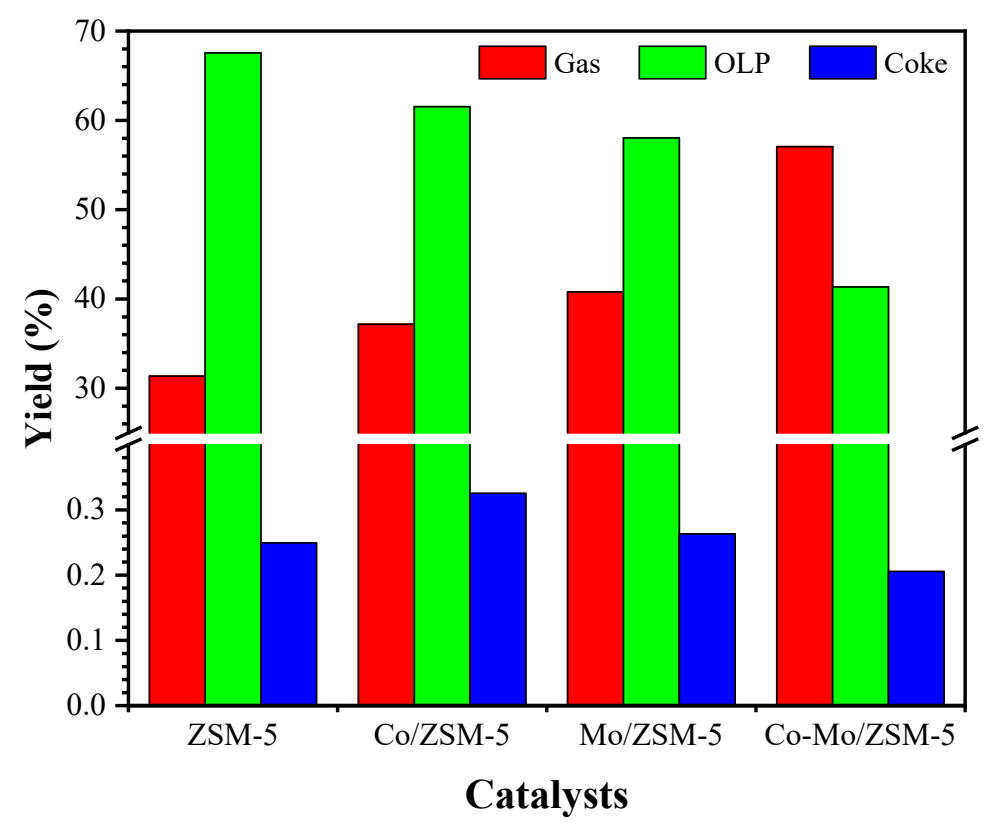

Figure 4. Catalytic performances of Co- and Mo-impregnated ZSM-5 catalysts.

\subsection{Organic Liquid Product Distribution}

The component distribution of the liquid product is presented in Table 2. As seen in Table 2, the liquid product contains hydrocarbon, alcohol, ketone, and ester components. It is clear that the main component in the liquid product is hydrocarbons, followed by alcohol components. Moreover, all of the modified ZSM- 5 catalysts produce higher hydrocarbon components than the parent ZSM-5. It confirms that the Co and Mo modification can increase the catalyst activity to produce hydrocarbons-rich biofuels. On the other hand, it is found that the fatty acid compounds are not detected, which confirms that the deoxygenation reaction occurred. The deoxygenation reactions can be decarbonylation and/or decarboxylation. The decarbonylation produces olefin and carbon monoxide and water as the by-product. On the other hand, the decarboxylation produces paraffin and carbon dioxide as the by-product [28]. As the hydrocarbon components are dominant, it is suggested that the deoxygenation reactions occurred during the cracking process. As shown in Table 2, the hydrocarbon product seems to be proportional to the presence of the Lewis acid site. It is previously reported that the Lewis acid site is responsible for the deoxygenation reaction [2]. Interestingly, it can be seen that the hydrocarbon produced by Mo/ZSM-5 is slightly higher than Co/ZSM-5, even though the Lewis acid site amount of Co/ZSM-5 is higher than Mo/ZSM-5. This phenomenon can be explained by the fact that the metal center is different. Wang et al. [37,38] reported that the metal center is important in deoxygenation reaction. They reported that the presence of $\mathrm{Mo}^{4+}$ and $/$ or $\mathrm{Mo}^{6+}$ center in the Co-Mo catalysts increased the deoxygenation performance. This finding confirms the phenomenon that the hydrocarbon products produced by Mo/ZSM- 5 are slightly higher than Co/ZSM-5.

Table 2. Distribution of organic liquid product (OLP) components.

\begin{tabular}{ccccc}
\hline \multirow{2}{*}{ Component } & \multicolumn{4}{c}{ Composition (\%) } \\
\cline { 2 - 5 } & ZSM-5 & Co/ZSM-5 & Mo/ZSM-5 & Co-Mo/ZSM-5 \\
\hline Hydrocarbons & 84.32 & 91.50 & 95.26 & 88.65 \\
Alcohols & 11.44 & 6.74 & 4.74 & 5.92 \\
Ketones & 1.81 & 0.97 & 0.00 & 3.38 \\
Esters & 2.43 & 0.78 & 0.00 & 2.05 \\
\hline
\end{tabular}


Concerning the alcohol components, it is expected that they are produced by the hydrogenation of fatty acid. Since the produced alcohols are categorized as primary alcohols, the olefin's hydration to alcohols is not considered as one of the involved mechanisms. The hydrogenation of a fatty acid, a carboxylic acid, produces alcohol. In this study, the hydrogen was not injected into the reactor. However, since the deoxygenation reactions, including decarbonylation and decarboxylation, occur during the cracking process, the water-gas shift (WGS) reaction is also expected to occur. The fact that carbon monoxide and water from deoxygenation reactions can react to each other through the WGS reaction, producing hydrogen and carbon dioxide, was confirmed by Sahebdelfar and Ravanchi [39]. Therefore, it is suggested that the hydrogen molecules are produced through the WGS reaction. On the other hand, the hydrogen molecule can also be produced by the dehydrogenation of paraffin to olefins and aromatic compounds. This mechanism can occur since the Lewis acid site is presented. It is known that the Lewis acid site is responsible for the dehydrogenation reaction of hydrocarbons [34]. Therefore, it is suggested that the hydrogens are produced through WGS and dehydrogenation reactions. Furthermore, the hydrogenation reaction of fatty acid occurs, producing alcohol molecules.

\subsection{Hydrocarbons Product Distributions}

As reported in the previous section (Section 2.3), hydrocarbons are the highest components in liquid products. The hydrocarbons are produced by the deoxygenation reactions, as explained in Section 2.3. Figure 5 shows the distribution of hydrocarbon components in the liquid products. It is clear that the hydrocarbon components are mostly included in the range below the $C_{12}\left(\leq C_{11}\right)$ (inset table in Figure 5$)$. Recalling the palm oil components (Table 3), the main fatty acids in the palm oil are palmitic acid (hexadecanoic acid) and oleic acid (octadecenoic acid), with total carbons of 16 and 18, respectively. Since the deoxygenation reactions, decarbonylation and decarboxylation reactions, can only produce hydrocarbons with one carbon shorter than the fatty acids $[40,41]$, the deoxygenation reactions can only produce hydrocarbons of $C_{15}$ and $C_{17}$. Therefore, the hydrocarbons with a low carbon range are produced by the further cracking reaction of the hydrocarbons.

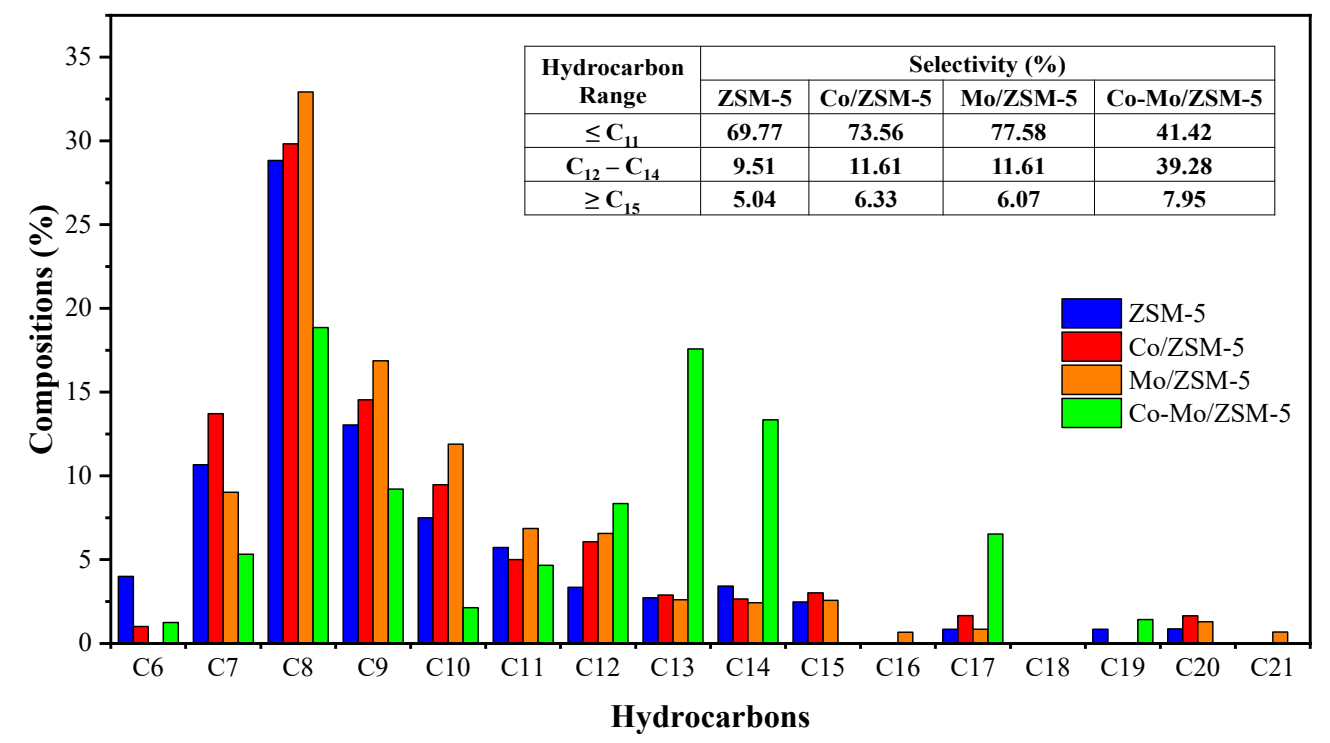

Figure 5. Distribution of hydrocarbons in liquid products. 
Table 3. Palm oil composition as a raw material.

\begin{tabular}{lcc}
\hline \multicolumn{1}{c}{ Components } & Molecular Formula & Composition (\%) \\
\hline Palmitic acid (C16:0) & $\mathrm{C}_{16} \mathrm{H}_{32} \mathrm{O}_{2}$ & 43.30 \\
Oleic acid (C18:1) & $\mathrm{C}_{18} \mathrm{H}_{34} \mathrm{O}_{2}$ & 18.51 \\
2-Monopalmitin & $\mathrm{C}_{19} \mathrm{H}_{38} \mathrm{O}_{4}$ & 3.25 \\
Z-13-Octadecenyl acetate & $\mathrm{C}_{20} \mathrm{H}_{38} \mathrm{O}_{2}$ & 2.03 \\
Oleic acid, & $\mathrm{C}_{39} \mathrm{H}_{76} \mathrm{O}_{3}$ & 1.47 \\
3-(oxtadecyloxy)propyl ester & $\mathrm{C}_{19} \mathrm{H}_{38}$ & 16.27 \\
1-Nonadecene & $\mathrm{C}_{26} \mathrm{H}_{50}$ & 5.80 \\
11-Hexacosyne & $\mathrm{C}_{23} \mathrm{H}_{46}$ & 5.68 \\
9-Tricosene & $\mathrm{C}_{15} \mathrm{H}_{30} \mathrm{O}$ & 1.34 \\
2-Pentadecanone & $\mathrm{C}_{19} \mathrm{H}_{34} \mathrm{O}$ & 1.18 \\
(Z,Z)-3,9-cis-6,7-epoxy- & $\mathrm{C}_{17} \mathrm{H}_{36} \mathrm{O}$ & 1.17 \\
nonadecadiene & & \\
1-Heptadecanol & & \\
\hline
\end{tabular}

As shown in Figure 5, the distributions of hydrocarbons are mainly at $\leq \mathrm{C}_{11}$. It confirms that the further cracking of hydrocarbons from deoxygenation reactions has occurred. However, it is found that the hydrocarbons produced by the Co-Mo/ZSM-5 are distributed at $\leq \mathrm{C}_{11}$ and $\mathrm{C}_{12}-\mathrm{C}_{14}$ with relatively proportional selectivity, $41.42 \%$ and $39.28 \%$, respectively. This exception occurs due to the different total acid site amounts of the catalyst. As shown in Table 1 and Figure 3, it is clear that the Co-Mo/ZSM-5 catalyst has the lowest acid site amount. Therefore, it is deduced that the total acid site amount is highly responsible for the cracking reaction, as reported in some previous studies [2,28]. In addition, it can also be deduced that the co-impregnation of Co and Mo on the ZSM5 catalyst could reduce the total acid site and reduce the cracking reaction so that the hydrocarbon products are highly distributed. Therefore, the hydrocarbon products are not only $\leq C_{11}$, which are the main components of the gasoline fraction, but also $C_{12}-C_{15}$, corresponding to the kerosene fraction.

The hydrocarbons in the liquid products are not only paraffin and olefins, which are straight-chain hydrocarbons, but also naphthenes and aromatics are found. The cracking process is highly suggested to be a complex reaction involving dehydrogenation, cracking, oligomerization, and aromatization [42]. Therefore, the paraffin, olefins, naphthenes, and aromatics, commonly written as PONA, are analyzed in this study. The distributions of PONA compounds in hydrocarbons are presented in Figure 6. As can be seen, the dominant compounds are naphthenes, cyclo-hydrocarbons. Three catalysts, i.e., ZSM-5, Co/ZMS-5, and Mo/ZSM-5, produce naphthenes as the dominant compounds. These facts confirm that the catalysts have a high affinity to the cyclization reaction. Furthermore, aromatic compounds are produced by all catalysts. This fact ensures that the parent ZSM- 5 catalyst is selective in the aromatization reaction [43]. In addition, the aromatic compounds are produced by the presence of the Lewis acid site. It was reported that the Lewis acid site has a high affinity to dehydrogenation and aromatization reactions [42,44].

With respect to the cyclization and aromatization reactions, it can be seen in the inset table (Figure 6) that the Mo/ZSM-5 obtains the highest ratio of naphthenes-toolefins+paraffins and aromatics-to-olefins+paraffins. This fact confirms that the Mo impregnation to the ZSM-5 catalyst increases the cyclization and aromatization reactions. Some researchers reported that the $\mathrm{MoO}_{\mathrm{x}}$ center site has a high affinity to the aromatization reaction $[10,44]$. However, by incorporating Mo with Co, it is found that it decreases the aromatization reaction, as the Co-Mo/ZSM- 5 catalyst gives the lowest aromatic compounds, as well as the lowest ratio of naphthenes-to-olefins+paraffins and aromatics-toolefins+paraffins. 


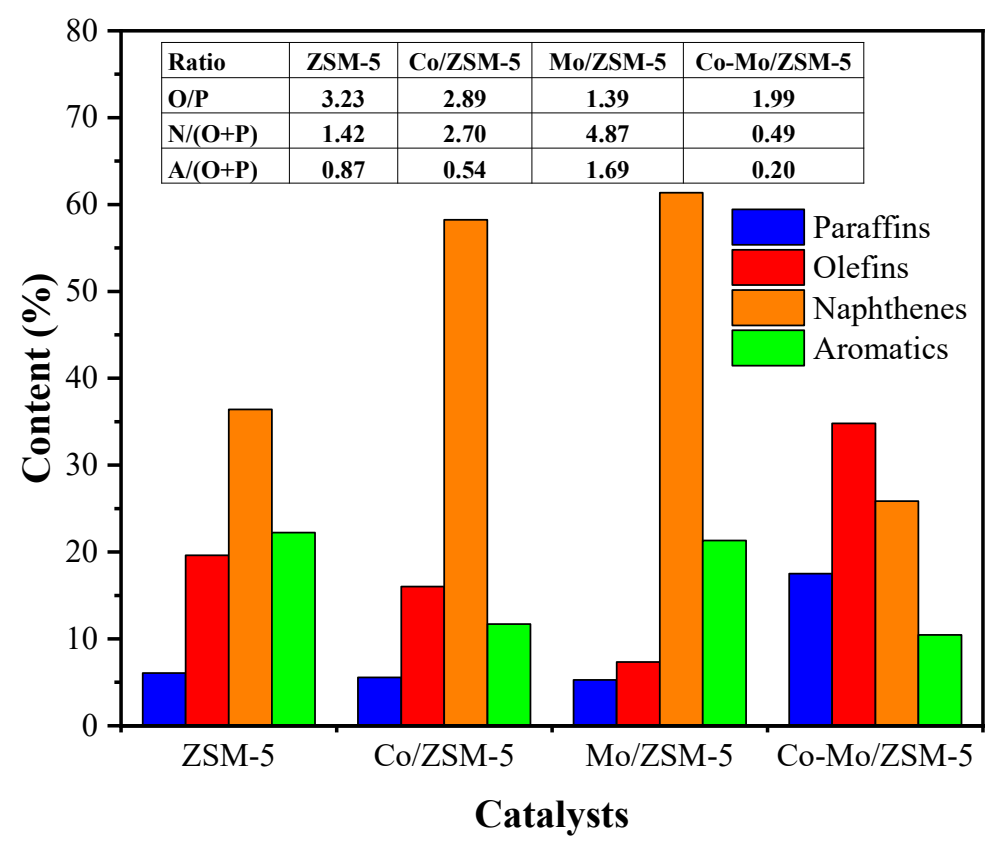

Figure 6. Distributions of paraffin, olefin, and aromatic components in the hydrocarbons.

\section{Materials and Methods}

\subsection{Materials of Research}

The ZSM-5 catalysts were obtained from Zeolyst International, commercially known as CBV 8014. Cobalt(II) Nitrate Hexahydrate (Merck KGaA, Darmstadt, Germany) and Ammonium Heptamolybdate Tetrahydrate (Merck KGaA, Darmstadt, Germany) were used as the precursors of $\mathrm{Co}$ and Mo. In order to evaluate the performance of the catalysts, palm oil from the local market was used as the feed of the cracking process. The composition of palm oil as a raw material is shown in Table 3. The composition was identified using GC-MS analysis [28]. Nitrogen gas (UHP, 99.99\%) was used as the flushing agent to flush all tubes and the reactor prior to the cracking process.

\subsection{Catalysts Preparation and Characterizations}

Prior to the impregnation process, the ZSM- 5 zeolite was dried at $110{ }^{\circ} \mathrm{C}$ for $3 \mathrm{~h}$ in an oven (Memmert, Schwabach, Germany). The wet impregnation method was used to load the Co and Mo metals onto the ZSM-5 zeolite. The solutions of metal precursors were prepared by dissolving the precursors in $250 \mathrm{~mL}$ of demineralized water. The precursors added were adjusted so that the metal loading on ZSM- 5 zeolite was 5\%, and the ratio of Co to Mo was 1:1. A certain amount of ZSM-5 zeolite was added to the solutions and stirred at room temperature for $3 \mathrm{~h}$. The slurry was filtered, and the solid obtained was dried in an electric oven (Memmert, Schwabach, Germany) at $110^{\circ} \mathrm{C}$ for $12 \mathrm{~h}$. The dried solid was then calcined in a muffle furnace (NEY VULCAN 3-550, Torrance, CA, USA) at $500{ }^{\circ} \mathrm{C}$ for $4 \mathrm{~h}$. The ZSM-5 zeolite without metal loading was denoted as ZSM-5. Meanwhile, Co/ZSM-5 denoted the ZSM-5 zeolite with Co loading, Mo/ZSM-5 denoted the ZSM-5 zeolite with Mo loading, and Co-Mo/ZSM-5 denoted the ZSM-5 zeolite with the co-impregnation of Co and Mo.

Some characterizations have been conducted to characterize the synthesized catalysts. X-ray diffraction (XRD) (Shimadzu 7000, Shimadzu Corporation, Nakagyo-ku, Kyoto, Japan) analysis was conducted using $\mathrm{Cu} \mathrm{K} \alpha$ radiation $(\lambda=1.54 \AA$ ). The diffractions patterns were generated at $2 \theta$ of $10-80^{\circ}$ with a scanning speed of $5^{\circ} \mathrm{min}^{-1}$. The relative crystallinity of the catalysts was calculated by comparing the diffraction quintet peaks area $\left(2 \theta=23-25^{\circ}\right)$ 
with the reference [12]. The ZSM-5 catalyst (without metal impregnation) was used as the reference. The relative crystallinity was estimated using the following equation:

$$
\% \text { Relative Crystallinity }=\frac{A_{i}}{A_{\text {ref }}} \times 100
$$

where $A_{i}$ stands for the diffraction quintet peaks area of sample and $A_{\text {ref }}$ stands for the diffraction quintet peaks area of ZSM-5. The X-ray fluorescence (XRF) analysis (Rigaku Supermini200, Applied Rigaku Technologies, Inc., Austin, TX, USA) was used to estimate the metal content. The Scanning Electron Microscopy (SEM, JEOL JSM-6510LA, Tokyo, Japan) method was used to investigate the surface morphology of the catalysts. $\mathrm{N}_{2}$ adsorption data were recorded using a ChemBET PULSAR (Quantachrome, Boynton Beach, FL, USA) at a relative pressure $\left(p / p^{\circ}\right)$ of $0.05-0.35$ to calculate the surface area of the catalyst using the Brunauer-Emmett-Teller (BET) surface area method. Prior to the $\mathrm{N}_{2}$-adsorption, the catalysts were degassed at $300{ }^{\circ} \mathrm{C}$ for $5 \mathrm{~h}$. The acidity and acid types of catalysts were determined using pyridine-probed FT-IR analysis. Prior to FT-IR analysis, pyridine was adsorbed into the catalysts, and the physisorbed pyridine molecule was evacuated at $150{ }^{\circ} \mathrm{C}$. The FTIR spectra were monitored at a wavenumber of $1600-1350 \mathrm{~cm}^{-1}$. The absorbance bands around 1545 and $1455 \mathrm{~cm}^{-1}$ are used to calculate the intensity of Brønsted and Lewis acid sites, respectively $[27,28]$.

\subsection{Catalytic Cracking Test}

The catalyst's performances were tested and evaluated in the palm oil continuous cracking reaction process. Figure 7 depicts the schematic diagram of the experimental setup for the palm oil cracking process. A stainless-steel pipe with an inside diameter of $2.54 \mathrm{~cm}$ was used as a reactor. The catalysts $(5 \mathrm{~g})$ were put inside the reactor, which was supported using glass wool. Prior to the reaction, nitrogen gas was flowed at $100 \mathrm{~mL} / \mathrm{min}$ for $30 \mathrm{~min}$ through the experimental rig to flush the oxygen trapped in the rig. The palm oil from the palm oil feedstock tank was fed using a peristaltic pump into the reactor. The palm oil flow rate was adjusted so that the weight hourly space velocity (WHSV) was $0.365 \mathrm{~min}^{-1}$. The cracking process was conducted at $450{ }^{\circ} \mathrm{C}$. The cracking products were condensed in the condenser. The condensed compounds (liquid products) were separated from the volatile compounds. The liquid products, known as Organic Liquid Products (OLP), were collected for $2 \mathrm{~h}$ after the process reached a steady state. The composition of the collected OLPs components was determined using gas chromatography-mass spectrometry (GC-MS) MS (QP2010S SHIMADZU, DB-1 column, Shimadzu Corporation, Nakagyo-ku, Kyoto, Japan). The samples were heated to and held at $50{ }^{\circ} \mathrm{C}$ for $5 \mathrm{~min}$, then ramped by $10^{\circ} \mathrm{C} / \mathrm{min}$ to $260^{\circ} \mathrm{C}$ and held for $33 \mathrm{~min}$. In order to evaluate the performance of the catalysts for palm oil cracking to biofuels, the yield of OLP, gas, and coke were used. The yield of OLP, gas, and coke were calculated using the following equation:

$$
Y_{i}(\%)=\frac{m_{i}}{m_{\text {feed }}} \times 100
$$

where $Y_{i}$ denotes the yield of component $i$ (OLP, gas, or coke), $m_{i}$ denotes the mass of component $i$, and $m_{\text {feed }}$ denotes the mass of palm oil fed to the reactor. 


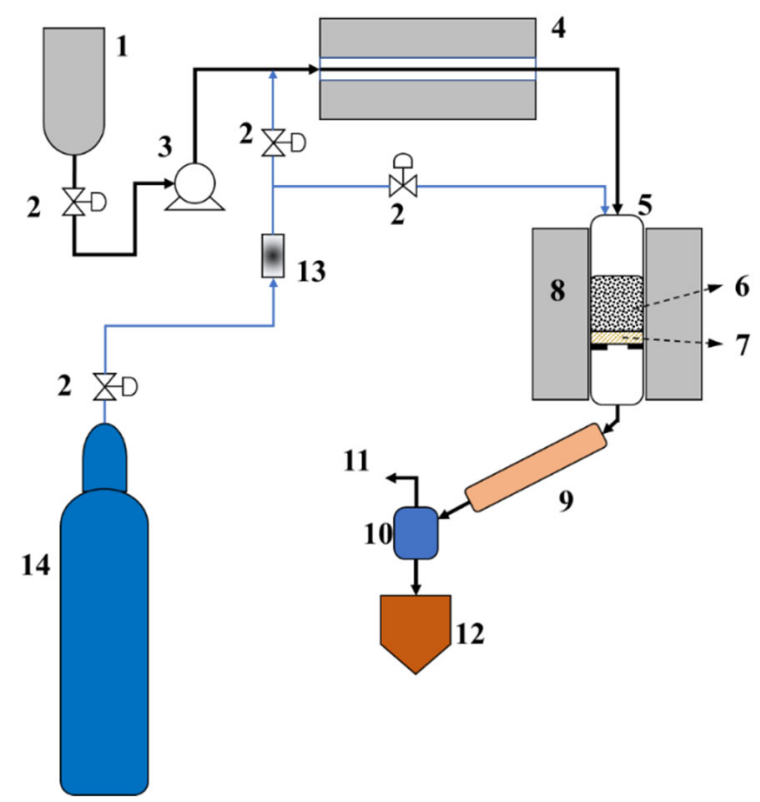

Figure 7. Schematic diagram of experimental set up of the continuous catalytic cracking process: (1) Palm oil feedstock tank, (2) gate valve, (3) peristaltic pump, (4) preheater, (5) reactor tube, (6) catalysts packing, (7) glass wool, (8) electric heating furnace as the reactor heater, (9) condenser, (10) gas-liquid separator, (11) gas by-product, (12) liquid fuels product, (13) gas flowmeter, and (14) Nitrogen gas tank.

\section{Conclusions}

In this study, Co and Mo have been successfully impregnated into the ZSM-5 catalyst. The impregnation of Co and/or Mo into ZSM-5 decreased the relative crystallinity, as well as the surface area of the catalysts because the metals partially blocked the pores and/or the pore mouths. The metals were dispersed in the catalysts, as proven by XRD and SEM analyses. As expected, the Lewis acid site was increased, and the B/L ratio was decreased by the impregnation of Co or Mo on the ZSM-5 catalyst. However, the co-impregnation of both Co and Mo on the ZSM-5 catalyst decreased the Lewis, and the total acid sites significantly and slightly increased the $\mathrm{B} / \mathrm{L}$ ratio because of the formation of the $\mathrm{CoMoO}_{4}$ metal cluster. The hydrocarbon's product selectivity was increased from $84.32 \%$ to $95.26 \%$; however, the impregnation of Co and/or Mo into the ZSM-5 catalyst decreased the liquid products (OLP) from $67.57 \%$ to $41.35 \%$. It was clearly confirmed that the single metal impregnation (Co or Mo) could increase the catalysts' activity to produce hydrocarbon-rich biofuels. However, the co-impregnation of Co and Mo to ZSM-5 could reduce the catalyst's activity. In addition, the incorporation/co-impregnation of Co and Mo into ZSM-5 changed the hydrocarbon distribution so that the hydrocarbon products were not only $\leq \mathrm{C}_{11}$ (the main component of gasoline fraction) but also $C_{12}-C_{15}$ (kerosene fraction). Moreover, the coke formation was decreased due to the low catalyst acidity. This property is expected to increase the catalyst lifetime due to a low deactivation by coke.

Author Contributions: Conceptualization, I.I. and T.R.; methodology, I.I., T.R. and B.J.; software, I.I.; validation, T.R., I.I. and B.J.; formal analysis, T.R.; investigation, T.R., A.A.P. and M.A.A.F.; resources, I.I.; data curation, D.D.A., T.R. and I.I.; writing-original draft preparation, T.R.; writingreview and editing, I.I. and B.J.; visualization, T.R. and I.I.; supervision, D.D.A., I.I. and B.J.; project administration, I.I. All authors have read and agreed to the published version of the manuscript.

Funding: Universitas Diponegoro: WCRU Scheme No. 118-22/UN7.6.1/PP/2021.

Data Availability Statement: Data is contained within the article. 
Acknowledgments: The authors would like to express their sincere gratitude to the Research Institution and Community Service, Universitas Diponegoro, Indonesia, for the financial support through the World Class Research Universitas Diponegoro (WCRU) research project category A with contract number: 118-22/UN7.6.1/PP/2021.

Conflicts of Interest: The authors declare no conflict of interest.

\section{References}

1. Musa, M.L.; Mat, R.; Abdullah, T.A.T. Catalytic Conversion of Residual Palm Oil in Spent Bleaching Earth (SBE) by HZSM-5 Zeolite based-Catalysts. Bull. Chem. React. Eng. Catal. 2018, 13, 456-465. [CrossRef]

2. Istadi, I.; Riyanto, T.; Buchori, L.; Anggoro, D.D.; Pakpahan, A.W.S.; Pakpahan, A.J. Biofuels Production from Catalytic Cracking of Palm Oil Using Modified HY Zeolite Catalysts over A Continuous Fixed Bed Catalytic Reactor. Int. J. Renew. Energy Dev. 2021, 10, 149-156. [CrossRef]

3. Ramya, G.; Sudhakar, R.; Joice, J.A.I.; Ramakrishnan, R.; Sivakumar, T. Liquid hydrocarbon fuels from jatropha oil through catalytic cracking technology using AlMCM-41/ZSM-5 composite catalysts. Appl. Catal. A Gen. 2012, 433-434, 170-178. [CrossRef]

4. Riyanto, T.; Istadi, I.; Buchori, L.; Anggoro, D.D.; Dani Nandiyanto, A.B. Plasma-Assisted Catalytic Cracking as an Advanced Process for Vegetable Oils Conversion to Biofuels: A Mini Review. Ind. Eng. Chem. Res. 2020, 59, 17632-17652.

5. Buzetzki, E.; Sidorová, K.; Cvengrošová, Z.; Kaszonyi, A.; Cvengroš, J. The influence of zeolite catalysts on the products of rapeseed oil cracking. Fuel Process. Technol. 2011, 92, 1623-1631. [CrossRef]

6. Gurdeep Singh, H.K.; Yusup, S.; Quitain, A.T.; Abdullah, B.; Ameen, M.; Sasaki, M.; Kida, T.; Cheah, K.W. Biogasoline production from linoleic acid via catalytic cracking over nickel and copper-doped ZSM-5 catalysts. Environ. Res. 2020, 186, 109616. [CrossRef] [PubMed]

7. Istadi, I.; Buchori, L.; Anggoro, D.D.; Riyanto, T.; Indriana, A.; Khotimah, C.; Setiawan, F.A.P. Effects of Ion Exchange Process on Catalyst Activity and Plasma-Assisted Reactor Toward Cracking of Palm Oil into Biofuels. Bull. Chem. React. Eng. Catal. 2019, 14, 459-467. [CrossRef]

8. Ibarra, Á.; Hita, I.; Azkoiti, M.J.; Arandes, J.M.; Bilbao, J. Catalytic cracking of raw bio-oil under FCC unit conditions over different zeolite-based catalysts. J. Ind. Eng. Chem. 2019, 78, 372-382. [CrossRef]

9. Hu, C.; Xiao, R.; Zhang, H. Ex-situ catalytic fast pyrolysis of biomass over HZSM-5 in a two-stage fluidized-bed/fixed-bed combination reactor. Bioresour. Technol. 2017, 243, 1133-1140. [CrossRef] [PubMed]

10. Botas, J.A.; Serrano, D.P.; García, A.; de Vicente, J.; Ramos, R. Catalytic conversion of rapeseed oil into raw chemicals and fuels over Ni- and Mo-modified nanocrystalline ZSM-5 zeolite. Catal. Today 2012, 195, 59-70. [CrossRef]

11. Haji Morni, N.A.; Yeung, C.M.; Tian, H.; Yang, Y.; Phusunti, N.; Abu Bakar, M.S.; Azad, A.K. Catalytic fast Co-Pyrolysis of sewage sludge-sawdust using mixed metal oxides modified with ZSM-5 catalysts on dual-catalysts for product upgrading. J. Energy Inst. 2021, 94, 387-397. [CrossRef]

12. Ding, J.; Chen, P.; Fan, S.; Zhang, Z.; Han, L.; Zhao, G.; Liu, Y.; Lu, Y. Microfibrous-structured SS-fiber@meso-HZSM-5 catalyst for methanol-to-propylene: Steam-assisted crystallization synthesis and insight into the stability enhancement. ACS Sustain. Chem. Eng. 2017, 5, 1840-1853. [CrossRef]

13. Huang, Z.; Zhang, J.; Li, P.; Xu, L.; Zhang, X.; Yuan, Y.; Xu, L. Tert-Butylation of naphthalene by tertiary butanol over HY zeolite and cerium-modified HY catalysts. Catal. Sci. Technol. 2017, 7, 4700-4709. [CrossRef]

14. Azzi, H.; Rekkab-Hammoumraoui, I.; Chérif-Aouali, L.; Choukchou-Braham, A. Mesoporous $\mathrm{Co}_{3} \mathrm{O}_{4}$ as a new catalyst for allylic oxidation of cyclohexene. Bull. Chem. React. Eng. Catal. 2019, 14, 112-123. [CrossRef]

15. Liu, J.; Jin, R.; Qiao, Y.; Wu, Y.; Wang, X.; Wang, Y. Determination of Lead(II) using glassy carbon electrode modified with hexagonal $\mathrm{Co}_{3} \mathrm{O}_{4}$ microparticles. Int. J. Electrochem. Sci. 2018, 13, 10415-10426. [CrossRef]

16. Al-Senani, G.M.; Deraz, N.M.; Abd-Elkader, O.H. Magnetic and Characterization Studies of $\mathrm{CoO}_{/} \mathrm{Co}_{3} \mathrm{O}_{4} \mathrm{Nanocomposite}$. Processes 2020, 8, 844. [CrossRef]

17. Wang, L.; Li, M.C.; Zhang, G.H.; Xue, Z.L. Morphology evolution and quantitative analysis of $\beta-\mathrm{MoO}_{3}$ and $\alpha-\mathrm{MoO}_{3}$. High Temp Mater. Process. 2020, 39, 620-626. [CrossRef]

18. Sen, S.K.; Dutta, S.; Khan, M.R.; Manir, M.S.; Dutta, S.; Al Mortuza, A.; Razia, S.; Hakim, M.A. Characterization and Antibacterial Activity Study of Hydrothermally Synthesized h- $\mathrm{MoO}_{3}$ Nanorods and $\alpha-\mathrm{MoO}_{3}$ Nanoplates. Bionanoscience 2019, 9, 873-882. [CrossRef]

19. Kheffache, O.; Lopez-Olmos, C.; Rodriguez-Ramos, I.; Cherifi, O. Clean 3,4-dihydropyrimidones synthesis via biginelli reaction over supported molybdenum: Structural and textural characteristic of $\alpha \mathrm{MoO}_{3}$. Bull. Chem. React. Eng. Catal. 2020, 15, 698-713. [CrossRef]

20. Al-Wadaani, F.; Omer, A.; Abboudi, M.; Oudghiri Hassani, H.; Rakass, S.; Messali, M.; Benaissa, M. High Catalytic Efficiency of Nanostructured $\beta-\mathrm{CoMoO}_{4}$ in the Reduction of the Ortho-, Meta- and Para-Nitrophenol Isomers. Molecules 2018, $23,364$. [CrossRef] [PubMed]

21. Li, W.; Wang, X.; Hu, Y.; Sun, L.; Gao, C.; Zhang, C.; Liu, H.; Duan, M. Hydrothermal Synthesized of CoMoO $\mathrm{C}_{4}$ Microspheres as Excellent Electrode Material for Supercapacitor. Nanoscale Res. Lett. 2018, 13, 120. [CrossRef] [PubMed]

22. Araujo, C.P.B.; De Souza, C.P.; Maia, L.M.D.; Souto, M.V.M.; Barbosa, C.M. On the synthesis of molybdenum carbide with cobalt addition via gas-solid reactions in a $\mathrm{CH}_{4} / \mathrm{H}_{2}$ atmosphere. Brazilian J. Chem. Eng. 2016, 33, 577-588. [CrossRef] 
23. Trisunaryanti, W.; Triyono, T.; Ghoni, M.A.; Fatmawati, D.A.; Mahayuwati, P.N.; Suarsih, E. Hydrocracking of Calophyllum inophyllum Oil Employing $\mathrm{Co}$ and/or Mo Supported on $\gamma-\mathrm{Al}_{2} \mathrm{O}_{3}$ for Biofuel Production. Bull. Chem. React. Eng. Catal. 2020, 15, 743-751. [CrossRef]

24. Yigezu, Z.D.; Muthukumar, K. Biofuel production by catalytic cracking of sunflower oil using vanadium pentoxide. J. Anal. Appl. Pyrolysis 2015, 112, 341-347. [CrossRef]

25. Lowell, S.; Shields, J.E.; Thomas, M.A.; Thommes, M. Surface Area Analysis from the Langmuir and BET Theories. In Characterization of Porous Solids and Powders: Surface Area, Pore Size and Density. Particle Technology Series; Springer: Dordrecht, The Netherlands, 2004; pp. 58-81, ISBN 1205420207.

26. Khabtou, S.; Chevreau, T.; Lavalley, J.C. Quantitative infrared study of the distinct acidic hydroxyl groups contained in modified Y zeolites. Microporous Mater. 1994, 3, 133-148. [CrossRef]

27. Devassy, B.M.; Halligudi, S.B. Effect of calcination temperature on the catalytic activity of zirconia-supported heteropoly acids. J. Mol. Catal. A Chem. 2006, 253, 8-15. [CrossRef]

28. Istadi, I.; Riyanto, T.; Khofiyanida, E.; Buchori, L.; Anggoro, D.D.; Sumantri, I.; Putro, B.H.S.; Firnanda, A.S. Low-oxygenated biofuels production from palm oil through hydrocracking process using the enhanced Spent RFCC catalysts. Bioresour. Technol. Reports 2021, 14, 100677. [CrossRef]

29. Vieira, S.S.; Magriotis, Z.M.; Ribeiro, M.F.; Graça, I.; Fernandes, A.; Lopes, J.M.F.M.; Coelho, S.M.; Santos, N.A.V.; Saczk, A.A. Use of HZSM-5 modified with citric acid as acid heterogeneous catalyst for biodiesel production via esterification of oleic acid. Microporous Mesoporous Mater. 2015, 201, 160-168. [CrossRef]

30. Stratiev, D.; Shishkova, I.; Ivanov, M.; Dinkov, R.; Georgiev, B.; Argirov, G.; Atanassova, V.; Vassilev, P.; Atanassov, K.; Yordanov, D.; et al. Role of Catalyst in Optimizing Fluid Catalytic Cracking Performance during Cracking of H-Oil-Derived Gas Oils. ACS Omega 2021, 6, 7626-7637. [CrossRef] [PubMed]

31. Anggoro, D.D.; Buchori, L.; Silaen, G.C.; Utami, R.N. Preparation, characterization, and activation of Co-Mo/Y zeolite catalyst for coal tar conversion to liquid fuel. Bull. Chem. React. Eng. Catal. 2017, 12, 219-226. [CrossRef]

32. Sadiq, M.; Sahibed-dine, A.; Baalala, M.; Nohair, K.; Abdennouri, M.; Bensitel, M.; Lamonier, C.; Leglise, J. Influence of acid-base properties of cobalt-molybdenum catalysts supported on magnesium orthophosphates in isomerization of 3,3-dimethylbut-1-ene. Arab. J. Chem. 2011, 4, 449-457. [CrossRef]

33. Sridhar, A.; Rahman, M.; Infantes-Molina, A.; Wylie, B.J.; Borcik, C.G.; Khatib, S.J. Bimetallic Mo-Co/ZSM-5 and Mo-Ni/ZSM-5 catalysts for methane dehydroaromatization: A study of the effect of pretreatment and metal loadings on the catalytic behavior. Appl. Catal. A Gen. 2020, 589, 117247. [CrossRef]

34. Yue, Y.; Fu, J.; Wang, C.; Yuan, P.; Bao, X.; Xie, Z.; Basset, J.M.; Zhu, H. Propane dehydrogenation catalyzed by single Lewis acid site in Sn-Beta zeolite. J. Catal. 2021, 395, 155-167. [CrossRef]

35. Feng, R.; Bai, P.; Liu, S.; Zhang, P.; Liu, X.; Yan, Z.; Zhang, Z.; Gao, X. The application of mesoporous alumina with rich Brönsted acidic sites in FCC catalysts. Appl. Petrochemical Res. 2014, 4, 367-372. [CrossRef]

36. Li, C.; Ma, J.; Xiao, Z.; Hector, S.B.; Liu, R.; Zuo, S.; Xie, X.; Zhang, A.; Wu, H.; Liu, Q. Catalytic cracking of Swida wilsoniana oil for hydrocarbon biofuel over Cu-modified ZSM-5 zeolite. Fuel 2018, 218, 59-66. [CrossRef]

37. Wang, W.; Yang, Y.; Bao, J.; Luo, H. Characterization and catalytic properties of Ni-Mo-B amorphous catalysts for phenol hydrodeoxygenation. Catal. Commun. 2009, 11, 100-105. [CrossRef]

38. Wang, W.; Yang, Y.; Luo, H.; Hu, T.; Liu, W. Amorphous Co-Mo-B catalyst with high activity for the hydrodeoxygenation of bio-oil. Catal. Commun. 2011, 12, 436-440. [CrossRef]

39. Sahebdelfar, S.; Ravanchi, M.T. Deoxygenation of propionic acid: Thermodynamic equilibrium analysis of upgrading a bio-oil model compound. Renew. Energy 2017, 114, 1113-1122. [CrossRef]

40. Simakova, I.; Rozmysłowicz, B.; Simakova, O.; Mäki-Arvela, P.; Simakov, A.; Murzin, D.Y. Catalytic deoxygenation of C18 fatty acids over mesoporous Pd/C catalyst for synthesis of biofuels. Top. Catal. 2011, 54, 460-466. [CrossRef]

41. Simakova, I.; Simakova, O.; Mäki-Arvela, P.; Simakov, A.; Estrada, M.; Murzin, D.Y. Deoxygenation of palmitic and stearic acid over supported Pd catalysts: Effect of metal dispersion. Appl. Catal. A Gen. 2009, 355, 100-108. [CrossRef]

42. Rane, N.; Kersbulck, M.; van Santen, R.A.; Hensen, E.J.M. Cracking of n-heptane over Brønsted acid sites and Lewis acid Ga sites in ZSM-5 zeolite. Microporous Mesoporous Mater. 2008, 110, 279-291. [CrossRef]

43. Liu, C.; Deng, Y.; Pan, Y.; Gu, Y.; Qiao, B.; Gao, X. Effect of ZSM-5 on the aromatization performance in cracking catalyst. J. Mol. Catal. A Chem. 2004, 215, 195-199. [CrossRef]

44. Kostyniuk, A.; Key, D.; Mdleleni, M. Effect of Fe-Mo promoters on HZSM-5 zeolite catalyst for 1-hexene aromatization. J. Saudi Chem. Soc. 2019, 23, 612-626. [CrossRef] 